pain and the symptoms and history of the case, it was obvious that the right kidney was the source of the pus. There was great hectic and wasting. Astringente, as gallic acid, alum, sulphuric acid, and tonics, as quinine, were freely administered, and in somewhat large and frequently repeated doses : thus, the gallic acid, alum, and sulphuric acid were usually given in scruple doses. Notwithstanding this treatment, and although the urine became much less offensive, the quantity of pus secreted continued very large, and in consequence the emacia. tion and debility greatly increased.

The remedies were, however, still persevered with. A draught of sedative solution of opium was given each night, with sulphuric acid, to check the profuse sweating; decoction of pomegranate fruit bark was also taken, and the fresh fruit freely eaten. At length slowly the symptoms began to amend; the pus gradually diminished in amount, but continued to be discharged in greater or less quantity for some five or six months.

After some advance had been made towards recovery, a concentrated decoction of uva ursi was given in large doses with considerable benefit, so that at the end of abont the seventh month the urine became bright and clear, while the patient had in a great measure recovered his flesh, strength, and health.

From the history given, it is obvious that this case was the result of repeated attacks of inflammation of the kidney, or nephritis, and therefore was one of inflammatory pyelitis, a somewhat rare disease. There was no taint of scrofula in the patient, and the symptoms were different from those which would characterize tubercular pyelitis. I attribute the successful result in this very extr me case to three circumstancesthe strength of the patient's stomach, the large doses of powerful astringents ordered, and lastly the perseverance of our patient in taking the remedies prescribed with the urmost regularity.

The second case I am about to narrate was that of a gentleman resident in Maidstone, who consulted me in the autumn of 1862 . He was about fifty years of age, stout, and of sanguineous temperament. During the previous four or five years he had passed several renal calculi; the last of these voided was brought to me, and was found to consist of uric acid, with a coating of earthy phosphates. On the 23rd of September, 1862, he had a very severe attack of spasmodic pain in the left loin and side, with retraction of testicle, indicating an effort to throw off another renal calculus, which, however, did not come aw.ty. In the beginning of October, he began to pass pus in the urine, while in November it happened on one or two occasions that the urine passed was perfectly olear. Its condition improved for a time under the free use of buchu. In February, 1863, severe pain again set in, and after an attack of violent vomiting, induced by a dose of opium, the pain went away for three weeks, a result attributable, perhaps, to the calculus having shifted its position; it, however, did not escape. The urine then became clear at intervals for two or three days at a time, but the pus re-appeared during the intervening periods; and in this alternating condi-ion it continued wntil the beginning of A pril, at which date a lump was noticed in the left lumbar region, precisely in the situation of the kidney. This was hard, circumscribed, painful, and of about the size of an egg. When the urine became clear and free from pus the swelling sensibly increased, but when the pus reappeared there was a diminution of size and a great relief from pain. Anodynes and astringents, as opium, buchu, alum, and gallic acid, were freely administered; and when the discharge had begun to reduce the patient's strength, and wasting and hectic had set in, quinine and iron were prescribed, as also sulphuric acid to moderate the sweating. The digestive powers being good, he could fortunately take plenty of nourishment, and his stomach was also able to bear the remedies prescribed.

The swelling, however, still continued to increase, and the pain at times was very distressing. On the 20th of May he wrote me word that he had been confined to his bed for the past fortnight, rolling abont at times in great pain, for the relief of which he was obliged to employ hot bran bags, hip-baths, chlorodyne, and chloroform; and he stated, further, that the tumour had become considerably enlarged, and that the urine had continued clear during most of the period. The pus now re-appeared, al though its aunount was much lessened; and great weakness and emaciation were induced; so that, from being a stout and powerful man, he was reduced to a state of extreme weakness, and was harassed with hectic and night-sweats. Quinine and iron were ordered, as well as nightdraughts containing sedative solution of opium, dilute sul phuric acid, and sulphate of zinc.

By the 5th of June the abscess had begun to point in the lumbar region and the integument to becom discoloured, although fluctuation could only be indistinctly determined. A day or two later it was opened by Mr. Harold. The quantity of pns which first came away was small; it, however, was of a very healthy character, and not at all offensive. Warm poultices were ordered, and by the 12th of June the abscess had begun to discharge pretty freely. Its size gradually less. ened, and the urine continued perfectly clear. The patient soon obtained sleep, and lost the hectic and night-sweats. From this period the progress of the case was steady. The abscess after a time ceased to discharge, and at length healed. and in two or three months the patient had thoroughly regained his strength and healtin.

This, then, is obviously a well-marked case of calculous pyelitis - that is, of inflammation of the substance of the kidney, terminating in suppuration, caused by the irritation of a calculus. It fortunately accurred in a very favourable subject for such a disease-that is, in a strong and bealthy man with good digestive powers, and in one, moreover, who, feeling the critical nature of his case, did all he could to second the efforts of his physician.

The recovery is complete. The urine is perfectly free from any deposit, and the patient nearly as vigorous as he ever was, although probably the substance of the kidney in which the abscess occurred has been entirely destroyed, and the work of depuration has now to be carried on by the remaining kid. ney, which has doubtless become to some extent enlarged or hypertrophied, to enable it the better to accomplish the greatly increased work which it has now to perform. The calculus, the cause of all the mischief, is no doubt very large, and it is remarkable that to this date it has neither escaped by the urethra nor come away through the opening of the abscess, and consequently it remains impacted in the wasted kidney.

Wimpole-street, October 31st, 1864 .

\section{AN INSTRUMENT FOR CONTROLLING HAMORRHAGE IN THE OPERATION FOR HARE-LIP.}

By THOMAS SMITH, EsQ., F.R.C.S., ASSISTANT-SERGEON TO ST. BARTHOLOMEW'S AND THE CHILDREN'S HOSPITAL.

THE object of the instrument delineated in the adjoining woodcut is to facilitate the operation for hare-lip, by giving the operator a firm hold on the soft and yielding textures of the face, thereby rendering their division more easy; and, again, by controlling the hæmorrbage, and thus enabling the surgeon to give his undivide $l$ and deliberate attention to the accurate and artistic adaptation of the denuded edges of the lip.

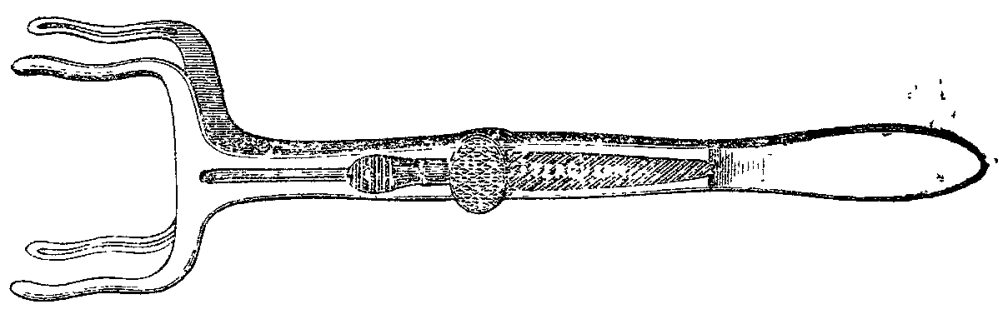

The instrument consists of a pair of forceps, of the shape indicated in the drawing; the blades are deeply grooved to hold the lip firmly, and one bandle is fitted with a sliding citch and button to admit of the forceps being fixed, and the degree of compression regulated at will. It is used in the following manner:-The upper lip being separated from its adbesion to the gum to the required extent, one blade of the forceps is pushed u' between the lip and gum, and the lip being grasped, the forceps are closed and fixed with the button; so that the fissure in the soft parts is surrounded, except at its upper angle, the coronary and other branches of the facial artery being thereby compressed. The operator, as is usual, should stand behind the patient, and having fixed the instrument, holding it by the handle, with one hand he may raise the lip from the jaw, while with the other he practises the necessary incisions. The edge of the fissure being pared, the sutures may be introduced, and the lip having been released from the gripe of the forceps, the sides of the cleft can be drawn together.

In some cases it is desirable to release the lip $f_{\text {i }}$ om the forceps before passing the sutures, in order that each suture may be 

passed throngh exactly opposite and corresponding points of
the fissure with more certainty.

The above-described instrument, or one very similar, may be used for controlling hæmorrhage in many operations on the lip or cheek, such as the removal of cancers or small tumours; it is also available in operations on nævus of these parts, to arrest the circulation in the growth while the disease is either excised or ligatured. Especially I would venture to recommend its ase when practicable for nævus of the face, treated by the injection of solution of perchloride of iron or other coagulating fluid, as I believe that thereby all risk of that rare though most fatal accident would be obviated-namely, the admixture of the injected fluid with the general stream of venous blood.

With the view of meeting the requirements of other operations on the face than hare-lip, Mr. Ferguson has been good enough to make an instrument similar to the one figured, but having movable arms, which expand so as to admit of adjustment to the extent of tissue requiring to be included within their grasp.

Montague-street, Russell-square, Oct. 1864.

\section{CONTRIBUTIONS}

Tо THE

\section{PATHOLOGY \& TREATMENT OF CERTAIN DISEASES OF THE HEART AND LUNGS.}

By A. T. H. WATERS, M.D., PHYSICIAN TO THE IIVERPOOU NORTHERN HOSPITAT.

\section{I.-THE CONDITION OF THE HEART IN EMPHYSEMA OF THE LUNGS.}

AMONGST the more prominent symptoms of general or lobar emphysema of the lungs is an altered condition of the heart. The expansion of the lungs pushes the cardiac organ down. wards, backwards, and towards the mesial line; so that in advanced states of the disease the beart is felt and seen to beat in the epigastrium beneath the ensiform cartilage; the cardiac region becomes resonant from the overlapping lung, and the lower site at which the sounds of the heart are best heard is altered. These are facts familiar to all who have given attention to pulmonary diseases, and it is not to them, but to certain changes which take place in the walls of the heart, that I wish to direct attention.

It has been the opinion of many pathologists that the right cavities of the heart alone become affected in emphysema; but the researches of Gairiner, Lebert, and others have satisfactorily proved that, in the majority of cases, where emphy sema is extensive and of long standing, the cardiac disease is not confined to one side. My own observations tend to con firm this opinion, and to show that the form of heart-disease most frequently associated with emphysema is a general hyper trophy and dilatation of the ventricles; for I have never seen a post.mortem examination of a case of extensive and longstanding lobar emphys ma in which the left ventricle, as well as the right, was not affected.

That this diseased condition of the heart is a consequence of emphysema we can have no difficulty in believing when we consider the nature of the lung affection, and especially that the palpitation, and other cardiac symptoms, are always pre ceded by dyspnoea and other signs of the pulmonary malady.

But hypertrophy of the ventricles is not the only change which takes place in the heart, for valvular disease is frequently found. The deposits which occur about the valses are no doubt secondary to the changes which take place in the muscular walls, and must be atrributed to the general mal-nutrition produced by the pulmonary disease.

Can we give any satisfactory explanation of the causes which lead to hypertrophy and dilatarion of the cavities of the heart in emphysema?

When we consider the anatomical arrangement of the pul. monary tissue, and especiully of the pulmonary bloodvessels in the disease, we can have $n$ ? doubt a $t$ the manner in which the right side of the heart becomes influenced. The impediment which exists to the circulation through the lungs, in consequence of the physical condition of the lung-tissue, and the imperfect aeration of the liloon, together with the diminution in the number of the pulmonary bloodvessels, must necessarily give rise to an overloaded state of the right cardiac cavities, and to increased action on their part.

No such explasation as that just given will, however, apply to the bypertrophy, so commonly found, of the left rentricle; for there is a diminution in the quantity of blood which finds its way into that cavity, and consequently, on this account, rather less call for muscular action than in a state of health. We might therefore infer that we have in these circumstances an element of atrophy, rather than of hypertrophy. But morbid anatomy teaches us that the latter usually exists. Whence, then, does it arise?

It appears to me that we must look, in great measure, for an explanation of the fact to the effect produced on the heart by the displacement it nudergoes in the disease. This displacement is always the greatest where the emphysema is most extensive, and it is in such cases that the left ventricle becomes most hyportrophied. As the lungs expand, the heart is pushed away from its normal position; and, consequently, the direction of the axis of its cavities is altered with reference to that of the vessels connected with them. The ventricles of the heart are so placed, in a s' ate of health, with regard to the arteries which issue from them, that no impediment exists to the onward passage of the blood, and the circulation is effected with the smallest possible expenditure of muscular force; but displace. ment of the heart necessarily alters the relations between these several parts, and produces an embarrassment of the heart's action-an embarrassment that can only be overcome by more powerful contraction. We consequently find that hypertrophy follows.

This appears to me to be the chief reason that must be assigned for the occurrence of hypertrophy of the left ventricle in emphysema. It is true that, in consequence of the condition of the venous system, some increased force may be required on the part of the left ventricle, and thus another element for the production of hypertrophy may exist. The altered situation of the heart is, however, I believe, the main cause; and this must have an influence in producing the changes which take place in the right ventricle, but here another cause is also at work.

Amongst the symptoms of emphysema, resulting from the changes which $I$ have just referred to, must be enumerated the powerful impulse of the heart, often felt in the epigastric region, together with the smallness and feeble character of the pulse, as felt, for instance, at the wrist. A knowledge of the condition of the heart and of the state of the pulmonary circulation serves to explain these phenomena. The powerful impulse of the heart is the result of its hypertrophy, and embarrassment from position; whilst the smaliness of the pulse is due to the small quantity of blood which the left ventricle expels at each beat, and its feebleness to the fact that the force of the left ventricle is expended, in part, in overcoming the resistance which exists to the passage of the blood from the ventricle, in consequence of the altered position of the latter, and in part merely in distending the arterial tubes. The diminished circulation through the pulmonary tissue, and the accumulation of the blood in the venous portion of the circulating system, sufficiently account for the small quantity of that fiuid which the left ventricle has to react on at each beat.

Liverpool, Oct. 1864.

\section{ON THE MECHANISM OF SPEECH.}

\section{Bx ISAAC PIDDUCK, M.D.}

To compare the mechanism of speech to that of a musical instrument, the organ, for instance : the chest is the bellows; the abdomen is the blower; the throat is the windpipe; the larynx is the reed; and, besides these, the cartilages and vocal cords are the strings; showing that the sounds of the voice are produced by the combination of a wind and a stringed instrument.

The sound formed by the larynx (consisting of the rima or chink), the cartilages, and the vocal cords, is divided by the tongue, the palate, the cheek, the teeth, and the lips, into letters, syllables, words, and sentences. Upon the perfect formation and healthy condition of these several parts the strength, the rhythm, and the distinctness of the voice depend.

But to play skilfully on a musical instrument long and careful practice is required. All persons learn to speak, as some persons learn to sing, by the ear ; but very few either speak or 